Revista de la red interuniversitaria de estudios sobre las literaturas rioplatenses contemporáneas en Francia

17 | 2017

Hermetismo programático en la literatura rioplatense contemporánea (de 1980 a nuestros días)

\title{
Leer, tocar: de una mano a la otra
}

\section{Michel Lisse}

Université Paris-Est Créteil (ed.)

Translator. Laura Gentilezza

\section{(2) OpenEdition}

1 Journals

\section{Electronic version}

URL: http://journals.openedition.org/lirico/3959

DOI: $10.4000 /$ lirico.3959

ISSN: 2262-8339

\section{Publisher}

Réseau interuniversitaire d'étude des littératures contemporaines du Río de la Plata

\section{Electronic reference}

Michel Lisse, «Leer, tocar: de una mano a la otra », Cuadernos LIRICO [En línea], 17 | 2017, Puesto en línea el 17 diciembre 2017, consultado el 01 mayo 2019. URL : http://journals.openedition.org/ lirico/3959; DOI : 10.4000/lirico.3959

This text was automatically generated on 1 May 2019.

\section{(c) (i) (3)}

Cuadernos LIRICO está distribuido bajo una Licencia Creative Commons Atribución-NoComercialSinDerivar 4.0 Internacional. 


\title{
Leer, tocar: de una mano a la otra
}

\author{
Michel Lisse \\ Université Paris-Est Créteil (ed.) \\ Translation : Laura Gentilezza
}

\section{EDITOR'S NOTE}

En nombre de Cuadernos LIRICO agradecemos el acuerdo del autor para publicar esta traducción. El original en francés fue publicado en Chassay, Jean-François y Gervais, Bertrand (ed.), Paroles, textes et images. Formes et pouvoirs de l'imaginaire, Université du Québec à Montréal, Figura, Centre de Recherche sur le texte et l'imaginaire, $\mathrm{n}^{\circ}$ 19, vol. 2, p. 157-168, y está disponible en línea en http://oic.uqam.ca/sites/oic.uqam.ca/files/ documents/cf19-2-9-lisse-lire_toucher.pdf. Las notas de traducción se incluyen entre corchetes.

\section{Ontología de la mano}

1 Comencemos por una cita y el examen de algunas fotos. La cita está sacada de un texto de Jacques Derrida titulado « La mano de Heidegger ». En ese texto, sobre el que volveremos, Derrida estudia el privilegio acordado por Heidegger a la mano. No a las manos, sino a la mano, como privilegio del hombre. Sólo el hombre tiene la mano. La cita que voy a leer atañe a las fotografías de Heidegger, una escenografía donde el pensador pone en evidencia su mano o sus manos en la medida en que éstas se unen para formar sólo una:

El número de L'Herne (...) llevaba sobre la cubierta una fotografía de Heidegger que lo mostraba, elección estudiada y significativa, sosteniendo su pluma con las dos manos por encima de un manuscrito. (...) Heidegger (...) solo podía escribir con pluma, con una mano de artesano y no de mecánico (...). Desde ese momento, estudié todas las fotografías publicadas de Heidegger, especialmente en un álbum comprado en Friburgo (...). El juego y el teatro de las manos merecerían un seminario entero. Si bien no he renunciado a ello, insistiré ahora en la puesta en escena deliberadamente artesanalista del juego de manos, de la mostracióny de la demostración que allí se exhibe, se trate ya del mantenimiento de la pluma, de la 
maniobra del bastón que muestra antes que sostiene o del balde con agua cerca de la fuente. La demostración de las manos también es cautivante en el acompañamiento del discurso. Sobre la cubierta del catálogo, la única cosa que excede el marco, el de la ventana pero también el de la foto, es la mano de Heidegger. ${ }^{1}$

2 El volumen de la colección «Champs » de la editorial Flammarion donde está publicado el texto de Derrida reproduce, también, esta foto sobre la cubierta.

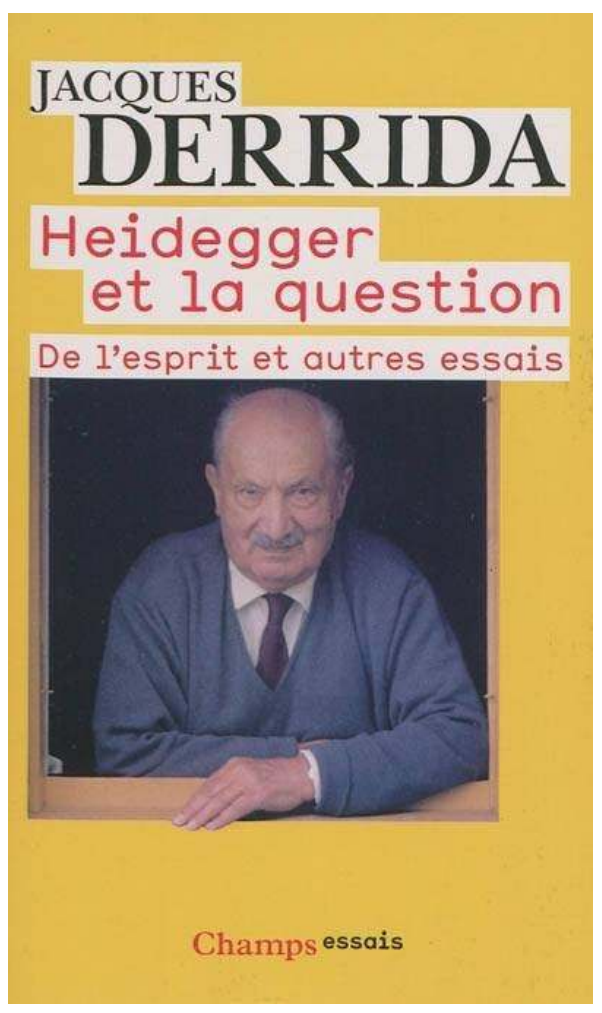

3 ¿Por qué nos interesaremos por el motivo de la mano? Derrida ve en el privilegio acordado a la mano del hombre en tanto que encarnación del tocar el principio más firme, más constante y más poderoso dentro de las tradiciones metafísicas ${ }^{2}$. Ahora bien, la puesta en primer plano de la mano que escribe es también un motivo recurrente que atraviesa el campo literario. Y la mano, lo vamos a leer en Heidegger, también está asociada a la lectura, no porque el pensador alemán tratara obras que se leen con una sola mano, sino porque postula una relación esencial entre el ser, la palabra hablada, la escritura manuscrita [manuscripture] y la lectura.

4 Heidegger, al menos desde Sein und Zeit, ha considerado la mano y la palabra mano (Hand) como constituyentes de su pensamiento. Procuró elaborar algunos de sus conceptos más importantes a partir de la palabra mano (Hand): Vorhandenheit [ser-ante-los-ojos] o Zuhandenheit [ser-a-la-mano], ${ }^{3}$ por ejemplo. La palabra mano (Hand) se volvió incluso esencial para acercar el pensamiento mismo, puesto que "pensar, es un trabajo de la mano, dice expresamente Heidegger » en ¿Qué significa pensar?". Pensar es un Hand-Werk. ¿Qué quiere decir esto?

Handwerk, el métier noble, es un métier manual que no se rige, como cualquier otra profesión, conforme a la utilidad pública o a los fines de lucro (HQ, p. 188) [LMH p. $19] .5$

5 Sin duda a Heidegger no le hubiera gustado la palabra métier, palabra francesa, demasiado francesa y latina, donde se pierde la mano. En todo caso, no dejó de llamar la atención en 
contra del pasaje del artesanado a la producción industrial. Se trate del carpintero, el pensador o el poeta, los tres corren el riesgo de ver su trabajo de la mano y con la mano puesto en peligro por la mecanización, corren el riesgo de perder la mano:

La mano está en peligro. Siempre: 'Todo oficio (Handwerk), toda actividad humana ( Handeln), está siempre expuesta a este peligro. La poesía (das Dichten) también está tan poco exenta de este peligro como el pensar (das Denken)' (p. 88 [p. 20], ligeramente modificada) La analogía es doble entre Dichten y Denken por un lado, pero también, por otro lado, entre ambos, poesía y pensamiento, y el auténtico trabajo de la mano (Handwerk) (HQ, p. 189) [LMH, p. 20].6

Heidegger reserva el término mano únicamente para el hombre. Escribe:

Órganos prensiles posee, por ejemplo [subraya Derrida], el mono, mas no tiene mano (Greiforgane besitzt z. B. der Affe, aber er hat keine Hand) (HQ, p. 192) [LMH, p. 23].

Derrida ve en ese pasaje un aspecto sintomático y dogmático de las aproximaciones metafísicas cuando se refieren a la animalidad. No desarrollaré este aspecto aquí, pero me gustaría de todos modos señalar que esta exclusión del animal y de los seres vivos en general fue retomada por Heidegger en sus textos tristemente célebres, puesto que corresponden a la época en que era rector de la Universidad de Friburgo bajo el régimen nazi. En un texto del 22 de enero de 1934, Heidegger declara:

El privilegio del trabajo (Arbeit) permanece negado al animal (...). ${ }^{7}$

Y al día siguiente:

(...) cualquier trabajo (Arbeit) en tanto que trabajo es espiritual (Geistig). El animal y

todo aquello que solamente vive no pueden trabajar. ${ }^{8}$

Vuelvo a la cuestión de la mano y a su relación con el pensamiento y comienzo la lectura de un texto ya comentado por Derrida. En el marco de un seminario sobre Parménides entre 1942-1943 ${ }^{9}$, Martin Heidegger dedicó una parte de la sesión a la escritura a mano, a la escritura manuscrita [manuscripture] (die Hans-schrift). Antes de ocuparse de la escritura, Heidegger va a insistir sobre la importancia de la mano en la relación del hombre con el ser y con el ente. Relación que compete a la esencia (si así traducimos Wesen) en tanto que el ente aparece primero como escondido por la mano, preservado por la mano: la mano cuida y preserva la relación entre el hombre y el ente y entre el hombre y el ser. La lengua (alemana, pero también francesa ${ }^{10}$ ) dispone de una expresión para manifestar la preservación de la esencia por parte de la mano: estar « en buenas manos » ( in guter Hand), incluso si la manipulación (Handgriff) es necesaria (y en este Handgriff entendemos la proximidad metafísica del concepto, el Begriff, la aprehensión conceptual, el contacto conceptual). Sin embargo, la mano que esconde, también revela. Heidegger va a tender un hilo que liga la mano, la palabra (Wort), el ser y la cosa (Ding): « la mano revela lo que había estado escondido en la medida en que muestra y dibuja mostrando, y en que dibujando construye signos que muestran formas terminadas $»^{11}$. La palabra se halla en ese gesto de mostración de la mano, en ese dibujo de la mano que es también un signo (Heidegger juega con la proximidad entre zeigt, zeigend, zeichnet, zeichnend, die zeigenden Zeichen). Más tarde, Heidegger escribirá que la palabra le acuerda el ser a la cosa o que « la palabra es lo que conduce a una cosa a ser cosa $»^{12}$.

10 La mano muestra la palabra, la dibuja, ese gesto se convierte en signo y encuentra su culminación en las formas. Estas formas, que provienen del dibujo, son llamadas grammata, de acuerdo con el verbo graphein (Platón ya en el Fedro asociaba la pintura y la escritura): «la palabra que es mostrada por la mano y que aparece en ese dibujo es la escritura $»^{13}$. De ahí la conclusión de Heidegger: considerar que la escritura es 
originariamente escritura manuscrita [manuscripture], escritura a mano: «la escritura es en su origen esencial escritura manuscrita [manuscripture] $»^{14}$. En este sentido, hay una definición de la lectura como recepción de lo oculto e intento de revelación basado en una escucha de la palabra escrita. Heidegger recuerda, como lo ha hecho a menudo, que el término alemán Lesen tiene como origen conjunto las palabras griegas leigen y logos: la recolección y el discurso, es decir, una cierta concentración. La mano reúne tanto los granos como las palabras. El ser, la palabra, la lectura, la escritura están asociadas a la mano que dibuja-escribe como origen esencial, brote y fuente originarios: «en la escritura a mano, la relación del ser con el hombre, es decir, la palabra, está inscripta y dibujada en el ente mismo $»^{15}$.

11 En cierto modo, aunque sin duda Heidegger lo hubiera rechazado, no estaba tan alejado de Hegel, cuando en La fenomenología del espíritu, más precisamente en un pasaje dedicado a la quiromancia, hace de la mano, al mismo tiempo, el órgano más cercano a la voz y el que fija el lenguaje:

[La mano] es después del órgano del lenguaje, el que más permite al hombre manifestarse y realizarse.

(...) [el] (...) lenguaje en cuanto adquiere por medio de la mano una existencia más fija y más sólida que por medio de la voz, (...) se convierte en lenguaje escrito, concretamente en su modalidad de escritura manuscrita (...). ${ }^{16}$

12 Hegel asociaba además las líneas simples de la mano al timbre y al volumen de la voz, que son las marcas de la determinabilidad individual del lenguaje.

13 Volvamos a Heidegger, que va a rastrear entonces el deterioro de la escritura situándola en la historia del ser. Este deterioro se produce cuando la escritura pierde la mano: esta amputación-mutilación es también una amputación-mutilación de la relación del hombre con el ser. Amputación-mutilación causada por la máquina:

Cuando le quitamos a la escritura su origen esencial, es decir la mano, y cuando la escritura es transferida a la máquina, en esos dos casos entonces, acontece un cambio en la relación del ser con el hombre. ${ }^{17}$

14 Y Heidegger se lamenta porque hoy (es decir en 1942), un gran número de hombres utilizan la máquina de escribir (die Schreibmachine) y una pequeña cantidad rehúye su utilización.

15 El primer momento de este deterioro se sitúa al principio de la Modernidad, en el momento de la invención de la imprenta, coincidencia que no se debe al azar.

16 Las palabras-signos, los signos de la palabra hablada van a convertirse en caracteres de imprenta, van a perder su enlace esencial, el que la escritura manuscrita [manuscripture] había preservado. Mientras que las letras van unidas por la mano que escribe, los caracteres de imprenta yuxtapuestos disuelven el enlace de la palabra.

17 Primero, los caracteres son dispuestos, luego prensados; esta asociación entre la disposición y la presión prenuncia la máquina de escribir que es «la efracción del mecanismo en el ámbito de la palabra $»^{18}$.

18 Pero cuando la imprenta (que aún era manual) se convierte en prensa rotativa, asistimos a un verdadero triunfo de la máquina. La era de la técnica es aquella en que « la máquina de escribir esconde el ser de la escritura; le quita al hombre la esencia de la mano, sin que el hombre perciba este despojamiento ni conozca que ya hay aquí una modificación de la relación del ser con el ser del hombre $»^{19}$. 
19 Nos equivocaríamos al pensar que Heidegger valoriza la escritura manuscrita [ manuscripture]. Esta no es más que un mal menor, pero participa de todos modos en el deterioro del pensamiento cuando éste deviene literatura en su sentido más amplio ${ }^{20}$ :

Esta evaluación aparentemente positiva del manuscrito no excluye, por el contrario, una desvalorización de la escritura en general. Cobra sentido en el marco de esta interpretación general del arte de escribir como destrucción creciente de la palabra y del habla. La máquina de escribir no es más que un agravante moderno del mal. Este no viene solamente por la escritura sino también por la literatura. (HQ, p. 203) [LMH, p. 33].

\section{Tocar los libros}

20 Abordemos ahora la problemática del tocar a partir del texto de Derrida Le toucher, JeanLuc Nancy y de determinados textos de Nancy. Una proximidad de pensamiento vincula a estos dos autores, incluso si ciertas diferencias se dejan leer (por ejemplo, sobre la cuestión de la deconstrucción del cristianismo). Proximidad entonces de un determinado pensamiento del tocar que será roce, caricia, tacto. " Acaríciame, no me toques », es la ley del tacto, enunciada bajo la forma de X $\sin X$, « hay que tocar sin tocar » (LT, p. 81) [ET, p. 105] con diversas variaciones: "tocar pero no tocar ", " tocar pero cuidando de evitar el contacto ", hay que poner en contacto « el contacto y el no-contacto ", hay que «tocar apenas » $(L T$, p. 83) $[E T$, p. 107].

21 No es posible entonces hablar sobre el tocar en general, sin abordar las cuestiones del « quién » o del « qué », no es posible abordar el tocar sin tocar al otro. Aristóteles puso en evidencia una de las aporías del tocar: «Mientras que cada sentido tiene un sensible propio (idion), el color para la vista, el sonido para el oído, el sabor para el gusto, el tacto tiene por objeto varias cualidades diferentes » (LT, p. 16) [ET, p. 26]; una aporía de este tipo implica pensar el tocar, no como « una sola y misma generalidad » con variaciones, sino como « una multiplicidad sin horizonte de unidad totalizable » (LT, p. 84) [ET, p. 109]. Por fuera, entonces, de toda hermenéutica y de toda fenomenología.

22 El tocar, Jean-Luc Nancy. El título, evidentemente, juega con la ambigüedad entre el nombre y el verbo, entre el nombre que designa el sentido y el verbo que designa la acción $^{21}$. Ocuparse del tocar en la obra de Jean-Luc Nancy consistirá igualmente en tocar a Jean-Luc Nancy. La escritura y la lectura son entonces una dirección, pero una dirección que permanece incierta, como quiere la ley del tacto: « ¿no era necesario también tocarlo a él, y tocar así a alguien, dirigirse singularmente a él, tocar a alguien en él, a un desconocido quizás?» (LT, p. 9) [ET, p. 15]. Leyendo a Nancy y dirigiéndole esta lectura, Derrida tocará quizás a un desconocido, incluso a un intruso, en Jean-Luc Nancy ${ }^{22}$.

23 En cuanto al libro, Nancy dirá que es una dirección $a$, que puede por supuesto tratar de, pero nunca sin dirigirse $a$, de manera que el contenido se vuelva indisociable del envío:

(...) el libro esencialmente le habla $a$, está dirigido, se dirige a sí mismo, se envía, se vuelve hacia un interlocutor que será entonces un lector. El libro no habla de, le habla $a$ o bien no habla de sin también hablarle $a(. ..) .^{23}$

Y si el libro es precisamente eso, una dirección, incluso una orden o una súplica, entonces sería un pedido continuamente renovado de lectura, que invalidaría cualquier noli me legere:

« ¡Léeme! ¡Léanme! » ( $Y$ esta súplica siempre murmura, incluso cuando el autor declara: « ¡No me lean! » o: « ¡Arroja mi libro! ») ( CP, p. 23). 
La lectura, tal como la piensa Nancy, es una cuestión de cuerpo, de cuerpo en contacto, en relación, pero de manera ínfima. Entre la mano que escribe y las manos que sostienen el libro abierto, existe el tocar, pero diferido por la técnica y por otros medios. Un tocar hecho de incesantes interrupciones, pero que persiste sin cesar:

Quiérase o no, los cuerpos se tocan en esta página \{esta página del libro llamado Corpus que estoy leyendo\}, o bien, ella misma es el punto de contacto (de mi mano que escribe, de las suyas que sostienen el libro). Este tocar \{subrayo\} es infinitamente desviado, diferido -máquinas, transportes, fotocopias, ojos, incluso otras manos se han interpuesto-, pero queda el ínfimo y rebelde grano, tenue (...) de un contacto por todas partes interrumpido y por todas partes reanudado. Al final, su mirada toca \{subrayo\} los mismos trazos de caracteres que toca \{subrayo\} ahora la mía, y ustedes me leen, y yo les escribo. ${ }^{24}$

Habría que evaluar las numerosas paradojas generadas por la cita de este fragmento en el contexto de un coloquio, fragmento primero leído, luego escrito, vuelto a copiar (pero jes una simple copia?), luego releído silenciosamente, para ser leído en público (¿quién es yo, quién es usted? Quizás el desconocido).

La escritura y la lectura ponen ejemplarmente en evidencia el tocar tal como Derrida y Nancy lo conciben: la distancia, la interrupción son sus condiciones de posibilidad:

Dos cuerpos no pueden ocupar simultáneamente el mismo lugar. O sea, usted y yo no podemos estar al mismo tiempo en el lugar donde yo escribo, en el lugar donde usted lee (...) No hay contacto sin separación (C, p. 51) [C, p. 46].

La escritura hace de algún modo salir el cuerpo de lo escrito, lo excribe [excrit], dice Nancy. $Y$ la lectura toca ese cuerpo y es tocada por él. Contacto con « el retiro infinito del sentido por el cual cada existencia existe $»^{25}$. Tocar un texto equivale a leerlo excrito, a tocar la certeza de una existencia, la de aquel o aquella que ha escrito el texto. Pero tocar ese cuerpo, es tocar la retracción del sentido. Escribir y leer son entonces una exposición (y una expeausition ${ }^{26}$ ) al no-saber. Es por eso que, me parece, Nancy invalida la lectura como desciframiento en beneficio del tocar sin inmediatez:

(...) hay que comprender la lectura como lo que no es el desciframiento: sino el tocar y el ser tocado, ocuparse de las masas del cuerpo. Escribir, leer, cuestión de tacto (C, p. 76) [C, p. 68].

Y para terminar, para ir hasta la punta extrema de la existencia, Nancy dirá que es en el corazón mismo donde el lector toca cuando toca el libro y cuando el libro lo toca, incluso si, en ese preciso momento, el tocar y la creencia, el tocar y el imaginario, se tocan:

Incluso tocar libros \{iquién toca y quién es tocado? ¿lector o libro?\} comunica \{al lector\} sus impresiones particulares: un peso, un grano, una elasticidad a través de los cuales uno creería \{subrayo\} discernir las inflexiones de una voz o las intermitencias de un corazón ( $C P$, p. 55).

\section{NOTES}

1. Jacques Derrida, «La main de Heidegger ", Heidegger et la question, París: Flammarion, 1990, p. 186; las referencias a este volumen se indicarán entre paréntesis, a continuación de la cita, 
precedidas de la mención $H Q$. [Las citas de este volumen se han establecido luego de cotejar con la siguiente versión castellana: Jacques Derrida, «La mano de Heidegger ", Trad. M. Rivera Hutinel, Revista Nombres, Universidad Nacional de Córdoba, nº 26, año XXI, 2012, en línea: https:// revistas.unc.edu.ar/index.php/NOMBRES/article/view/4750/4548, p. 17-18. Se conservarán entre paréntesis las referencias a la obra original de Derrida y se agregarán a continuación las correspondientes referencias a esta traducción castellana con las iniciales $\mathrm{LMH}$.]

2. Ver Jacques Derrida, Le toucher, Jean-Luc Nancy, París: Galillé, 2000, p. 85, nota 1; las referencias a este volumen se indicarán entre paréntesis, a continuación de la cita, precedidas por la mención LT. [Las citas de Derrida han sido establecidas luego de cotejar la versión castellana: Jacques Derrida, El tocar, Jean-Luc Nancy, Trad. I. Agoff, Buenos Aires: Amorrortu, 2011, p. 109-110, nota 3. Se conservarán entre paréntesis las referencias a la obra original de Derrida y se agregarán a continuación las correspondientes referencias a esta traducción castellana con las iniciales ET.]

3. [Estos términos acuñados por Heidegger han sido traducidos como indicamos entre corchetes por José Gaos en El ser y el tiempo (México: FCE, 1951), primera traducción castellana de Sein und Zeit (1927), que circuló como única versión en el mundo hispanohablante desde 1951 hasta 1997, cuando Jorge Eduardo Rivera presentó la suya, primero en Santiago de Chile y luego en España (Martin Heidegger, Ser y tiempo, Santiago: Universitaria, 1997 y Madrid: Trotta, 2003).]

4. [Michel Lisse trabaja aquí con dos textos: cita a Derrida desde Heidegger et la question y a su vez indica que Derrida está trabajando con Qu'appelle-t-on penser? (Martin Heidegger, Qu'appelle-t-on penser?, Trad. A. Becker y G. Granel, París: PUF, 1959), versión francesa de Was heißt denken? de Heidegger, donde se desarrollan estas ideas (Martin Heidegger, Was heißt denken?, Tubingen: Max Niemeyer Verlag, 1954). De esta obra utilizaremos la siguiente versión castellana para el cotejo de las citas: Martin Heidegger, ¿Qué significa pensar?, Trad. H. Kahnemann, Buenos Aires: Editorial Nova, 1972.]

5. [Elegimos conservar el término francés métier porque Lisse reflexiona acerca de esa palabra en el párrafo siguiente y se trata, además, de un galicismo cuyo uso es frecuente en castellano.]

6. [En esta cita de Derrida que Lisse reproduce, aparece una cita de Heidegger que corresponde a la p. 88 de Qu'appelle-t-on penser? y a la p. 20 de su versión castellana, ¿Qué significa pensar?, que también hemos modificado.]

7. Le débat, $\mathrm{n}^{\circ} 48,1988$, p. 190. [Lisse está citando un discurso dirigido a los trabajadores que Heidegger pronunció en la Universidad de Friburgo, durante el ejercicio de su rectorado (1933-1934), el 22 de enero de 1934. En 1988, antes de que se publicara la traducción francesa de la Edición integral de la obra de Heidegger, Éditions Verdier publica el libro de Victor Farías, Heidegger et le nazisme, donde se citan ampliamente los discursos de ese período. François Fédier, traductor de Heidegger, considera que esas traducciones son muy dudosas y por esto, en el dossier « Heidegger, la philosophie et le nazisme » del número 48 de Le débat, incluye la traducción de ese conjunto de textos al cuidado de Nicole Parfait, bajo el título « Textes politiques 1933-1934». En la introducción, Fédier alerta al lector sobre la interpretación que los discursos pueden tener en cuanto al vínculo de Heidegger con el nazismo.]

8. Ibid. Queda por revisar la elección por parte de Heidegger de la palabra Arbeit (muy presente en el Discurso del rectorado). ¿Por qué remplaza, en esa época y en ese contexto, la palabra Handwerk? 9. Martin Heidegger, Parmenides, Gesamtausgabe, Band 54, p. 124 y ss. Este texto no está traducido al francés, voy a lanzarme entonces a un arriesgado ejercicio a medio camino entre la traducción y la paráfrasis. Agradezco a Stéphanie Vanasten por su ayuda. [Cuando Michel Lisse escribe y publica este artículo (2008) efectivamente estos seminarios de Heidegger no estaban traducidos al francés. Sí estaban, en cambio, traducidos al castellano: Martin Heidegger, Parménides, Trad. C. Másmela, Madrid: Akal, 2005, p. 109 y ss. Actualmente también han sido traducidos al francés: Martin Heidegger, Parménide, Trad. T. Piel, París: Gallimard, 2011, p. 138 y ss.]

10. [Y también castellana.] 
11. [Esta traducción arriesgada por Lisse corresponde a la siguiente cita en la versión castellana de Parménides antes referida: « la mano indica, y por la indicación desoculta lo que está oculto; de este modo suscribe $\mathrm{y}$, en tanto suscribe formas, las suscribe indicándolas en formaciones » ( $\mathrm{p}$. 110).]

12. Martin Heidegger, Acheminement vers la parole, Trad. J. Beaufret, W. Brokmeier y F. Fédier, París: Gallimard, 1976, p. 208. [Esta es la versión francesa que Lisse consulta del original de Heidegger Uterwegs zur Sprache (Martin Heidegger, Uterwegs zur Sprache, Berlín: Verlag Gunter Neske Pfullingen, 1959): « Le mot est ce qui amène une chose à être chose ». La versión castellana de este texto fue publicada por Ediciones del Serbal-Guitard primero y luego por Odós: Martin Heidegger, De camino al habla, Trad. Y. Zimmermann, Barcelona: Odós [1987] 1990, p. 209): «La palabra 'en-cosa' la cosa en cosa ».]

13. [Martin Heidegger, Parménides, op. cit., p. 110: « La palabra indicada por la mano y que aparece en dicha suscripción es la escritura ».]

14. [Martin Heidegger, Parménides, op. cit., p. 110: «La escritura es, en su procedencia esencial, manus-crito ».]

15. [Martin Heidegger, Parménides, op. cit., p. 110: «En el manuscrito la referencia del ser al hombre, a saber, la palabra, está inscrita en el ente mismo ».]

16. Georg W. F. Hegel, La Phénoménologie de l'esprit, I, Trad. J. Hyppolite, París: Aubier Montaigne, 1941, p. 261, 262. [Lisse cita la celebrada traducción francesa de Jean Hyppolite de Phänomenologie des Geistes. Versión castellana: G.W.F. Hegel, Fenomenología del espíritu, Trad. W. Roges, México: FCE, 1966, p. 188-189. Las citas fueron traducidas tras cotejarlas con esta versión.]

17. [Martin Heidegger, Parménides, op. cit., p. 110: «Por tanto, cuando la escritura se retrae del origen de su esencia, es decir, de la mano, y es transferida al escribir de la máquina, acaecepropicia una transformación en la relación del ser con el hombre ».]

18. [Martin Heidegger, Parménides, op. cit., p. 111: «En la máquina de escribir encontramos la irrupción del mecanismo en el ámbito de la palabra ».]

19. [Martin Heidegger, Parménides, op. cit., p. 111: «La máquina de escribir vela la esencia del escribir y de la escritura. Ella sustrae del hombre el rango esencial de la mano sin que él experimente debidamente esta sustracción, y reconozca que aquí acaece-propicia ya una transformación de la referencia del ser a la esencia del hombre ».]

20. Ver Qu'appelle-t-on penser?, p. 91 [¿Qué significa pensar?, op. cit., p. 23]. Heidegger recuerda allí que Sócrates fue el pensador más puro de Occidente porque no escribió nada. Después de él, los pensadores perdieron de algún modo su pureza escribiendo, «el Pensamiento entró en la Literatura ", escribe Heidegger.]

21. [Recordamos que en francés el término toucher tiene al menos dos sentidos. Por un lado, designa el sentido del tacto y, por otro, el infinitivo del verbo «tocar». Existe, además, una interpretación en francés que no es traducible al castellano: la que permitiría considerar el artículo francés le del sintagma Le toucher, Jean-Luc Nancy como un pronombre de objeto directo, puesto que se escriben igual y el pronombre de objeto directo se antepone al verbo. Ese sintagma podría ser leído como «tocarlo », « tocarlo a Jean-Luc Nancy ». Para un análisis detallado de las dificultades de traducción de este término al castellano, véase: Irene Agoff, «Sobre la traducción », El tocar, Jean-Luc Nancy, op. cit., p. 91.]

22. Este texto ya estaba escrito cuando, durante mi estadía en Montreal, Ginette Michaud me regaló Trop. Encontré allí esta observación de Jean-Luc Nancy referida a las frases de Jacques Derrida: « el destinatario de la dirección, en esas frases, soy " yo » o bien es « Jean-Luc Nancy » del mismo modo que cualquier otro a quien Derrida le escribe aquí, (...) » (Galerie de l'Uqam, 2006, p. 91). [Michel Lisse se refiere al libro Nancytrop(es): pensées greffées, mêlées, mixées, preparado por Louise Déry, Georges Leroux y Ginette Michaud con motivo de la exposición TropJean-Luc Nancy avec Rodolph Burger et François Martin en la Galería de la Universidad de Quebec en Montreal, octubre-noviembre de 2005. No existe una traducción castellana de esta obra.] 
23. Jean-Luc Nancy, Sur le commerce des pensées, París: Galilée, p. 22, las referencias a este volumen se darán entre paréntesis, a continuación de la cita, precedidas por la mención CP [Versión castellana: Jean-Luc Nancy, Sobre el comercio de los pensamientos, Trad. V. Goldstein, Buenos Aires: La marca, 2016. Cabe destacar que este libro cuenta con ilustraciones originales de Jean Le Gac, para la versión francesa, y del maestro argentino Antonio Seguí, para la versión castellana. Se conservarán entre paréntesis las referencias a la obra original de Nancy que Michel Lisse introdujo con las iniciales $C P$.]

24. Jean-Luc Nancy, Corpus, París: Métailié, 2000, p. 47; las referencias a este volumen se darán entre paréntesis, a continuación de la cita, precedidas por la mención $C$. [Versión castellana: Jean-Luc Nancy, Corpus, Trad. P. Bulnes, Madrid: Arena Libros, 2003, p. 42. Las traducciones de las referencias a este volumen se hicieron cotejando esta versión. Se conservarán entre paréntesis las referencias a la obra original de Nancy y se agregarán a continuación las correspondientes referencias a esta traducción castellana con la inicial $C$. Vale recordar que la palabra francesa touche -que tradujimos por «toca »-, además de ser la forma conjugada del verbo toucher en presente del indicativo, designa la tecla del teclado. Lo señalamos porque el texto habla precisamente de las mediaciones que la tecnología interpone al tocamiento que suponen la escritura y la lectura. Una de esas mediaciones es la máquina de escribir o la computadora donde quien escribe toca las teclas, les touches. Incluso, si el sintagma anterior fuera pronunciado en francés, sonaría igual que el sintagma le touche, es decir « lo toco » o « lo toca ».]

25. Jean-Luc Nancy, Une pensée finie, París: Galilée, 1990, p. 61; las siguientes frases remiten a las páginas 62 y 63 del mismo libro. [Versión castellana: Jean-Luc Nancy, Un pensamiento finito, Trad. J. C. Moreno Romo, Barcelona: Anthropos, 2002, p. 44 y ss.]

26. [Conservamos la palabra en francés. Una traducción literal podría ser expielsición, aunque no significa nada en castellano. Michel Lisse toma el término de Jean-Luc Nancy quien realiza sobre la palabra francesa exposition una intervención similar a la que realiza Derrida sobre la palabra différence. Nancy reemplaza la o por el conjunto vocálico eau, apoyado en la homofonía -puesto que tanto o como eau se pronuncian /o/- y juega con el sentido de peau que significa « piel». El juego homofónico le permite inscribir una palabra dentro de otra y acuñar en ella una reflexión sobre el cuerpo.]

\section{AUTHORS}

\section{MICHEL LISSE}

Université catholique de Louvain 